occurring in this occupational group. This study aimed to assess the profile of professional drivers receiving sick leave benefits from the Brazilian National Institute of Social Security (INSS).

Methods This was a cross-sectional study involving 120 professional drivers receiving temporary sick leave benefits from INSS. The drivers were evaluated from November 2014 until December 2015 and submitted to a structured analysis for data collection including: gender, age, type of vehicle driving, driver's license type, ICD-10, absenteeism time, presence of chronic disability and current employment status.

Results The results showed that all drivers were male having a mean age of 54 years-old ranging from 24 to 71 years-old; truck drivers represented 47\%, bus drivers (27\%), and drivers of others vehicles (26\%), being mostly category D (68\%) and category E (20\%). Trough ICD-10, the study revealed the most affected diseases were cardiovascular (31\%) and musculoskeletal diseases (29\%). The mean absenteeism time was 62 days and 8\% developed chronic disability, 90\% kept the same post, accommodation was necessary in $8 \%$ of the cases, and $2 \%$ had disability retirement.

Discussion From these results, it is concluded that most professional drivers receiving sick leave benefits from INSS were adult males, category D truck drivers, presenting mainly with cardiovascular and orthopaedic diseases, absent from work for two months and some associated with chronic impairment. The results provide some evidence that Brazilian professional drivers are at risk for developing certain diseases. These data also should help companies to take measures for preventing work time loss and disability caused by these diseases, including for example health promotion.

\section{SICK LEAVE BY OCCUPATIONAL ACCIDENT: A RETROSPECTIVE EPIDEMIOLOGICAL STUDY}

RV Brito*, VR Batalini, AFA Lemos, AES Zafalon, CM Galhardi, LR Ferreira. Centro Universitário das Faculdades Associadas de Ensino - UNIFAE, São João da Boa Vista, Brazil

\subsection{6/oemed-2018-ICOHabstracts.879}

Introduction Wounds, illness and deaths caused in the work environment cost $\$ 21,46$ billion (2015) in Brazil, according to the Secretariat of Labour Inspection of Ministry of Labour. Contributing to this overview, the Sick Leave is a benefit granted by Brazilian National Social Security Institute (INSS), to workers who are victims of occupational accidents and become temporarily unable for work. In this context, the present study aims to evaluate the epidemiological profile of workers receiving sick leave by occupational accident, correlating data about illnesses, gender, occupational location and age group.

Methods A retrospective study based on analyses of 4.035 patients who requested sick leave by occupational accident from the Brazilian National Social Security Institute (INSS), characterising the age, gender, prevalence of urban and rural workers, more prevalent diseases associated with the occupational accidents through the ICD-10, from January 2014 to March 2017.

Results The study showed that the majority of 4.035 victims of the accidents with the benefit were male $(73,08 \%)$, associated with urban jobs (91,82\%) ranging from 30-39 years-old $(28,52 \%)$; rural jobs represented $8,17 \%$ ranging from $45-$ 54 years-old. The fractures of upper limb represented 25,41\% of all benefits, followed by fractures of lower limb $(18,33 \%)$, diseases of upper limb not associated with fractures $(12,48 \%)$ and diseases of lower limb not associated with fractures (6,16\%).

Discussion The profile of workers who were victims of occupational accidents that received disability benefits from INSS revealed that the majority of beneficiaries were male adults, working in urban jobs ranging from 30-39 years-old, associated mainly with diseases of upper limbs. These data should help in the implementation of measures to prevent the loss of work capacity caused by occupational accidents involving Brazilian workers. It's expected this prevent measures decrease the costs related to work environment.

\section{BRAZILIAN SUPERIOR LABOUR COURT AND THE RESPONSIBILITY OF THE EMPLOYER FOR ACCIDENT OR OCCUPATIONAL DISEASE: PREVENTIVE AND REPARATORY ACTIONS}

${ }^{1}$ SR Cavalcante*, ${ }^{1}$ RAG Vilela, ${ }^{2} \mathrm{GG}$ Feliciano. ${ }^{1}$ University of São Paulo - School of Public Health, São Paulo, Brazil; ${ }^{2}$ University of São Paulo - School of Law, São Paulo, Brazil

\subsection{6/oemed-2018-ICOHabstracts.880}

Introduction Brazil developed regulatory system and institutional structure to protect workers health and safety in the workplace. However, acidentes and diseases ocurrences remain high and great distance exists between legislation and voluntary law compliance. Brazilian laws provide procedural instruments to compensate the damage caused to workers health and to prevent future injuries. This survey verified how Brazilian Labour Judiciary are judging the actions regarding the companies liability in diseases and accidents at work, including the convictions values.

Methods Decisions published in 2015 that judged work-related accidents and diseases (individual and collective actions) were analysed consulting online Brazilian Superior Labour Court (TST) jurisprudence database. Data categorization was done considering the result (court application rejected or accepted), reasoning used by the judges and the compensation amount.

Result Labour High Court issued 231799 decisions in 2015, with $6.76 \%$ about work accidents and $0.12 \%$ on collective action and work accidents. The processes have been filed by Labour Prosecutor (83\%) and Unions (17\%). The compensation for collective moral damage had average of US\$73 530 . In individual reparatory actions, the employer had to compensate for worker health damage in $90 \%$ of cases, with high degree of sentences reformed (41\% to increase/deny and $4 \%$ to extinguish/reduce arbitrated values). The values arbitrated were between US\$65 000 and US\$1 32000 (fatal acidentes) and US\$4400 to US\$53000 (occupational diseases and other acidentes).

Discussion Although collective actions are little used, the labour judicial system provides the preventive protection requested: all judgments analysed granted compensation for collective moral damage and/or obligation to make changes to improve prevention and safety. The values of convictions arbitrated in collective actions are significant and indicate social and economic repercussions, stimulating employers to improve their companies working environment conditions. It is necessary to intensify the use of collective actions, because they are more efficient for prevention than reparatory individual lawsuits. 